
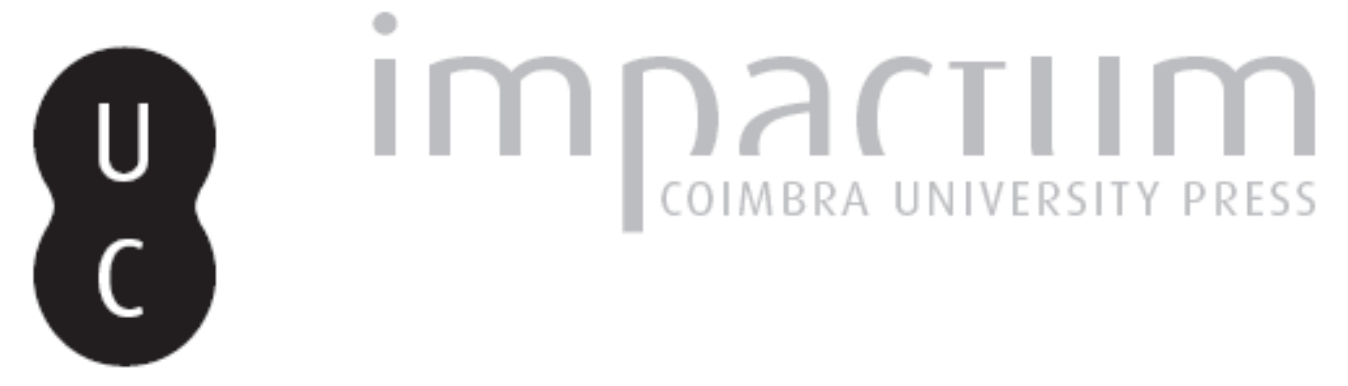

\title{
O acróstico do túmulo de Kheruef
}

\section{Autor(es): $\quad$ Carreira, Paulo}

Publicado por: Centro de História da Universidade de Lisboa

URL persistente:

URI:http://hdl.handle.net/10316.2/32976

DOI:

DOI:http://dx.doi.org/10.14195/0871-9527_22_4

Accessed : $\quad$ 26-Apr-2023 15:52:15

A navegação consulta e descarregamento dos títulos inseridos nas Bibliotecas Digitais UC Digitalis, UC Pombalina e UC Impactum, pressupõem a aceitação plena e sem reservas dos Termos e Condições de Uso destas Bibliotecas Digitais, disponíveis em https://digitalis.uc.pt/pt-pt/termos.

Conforme exposto nos referidos Termos e Condições de Uso, o descarregamento de títulos de acesso restrito requer uma licença válida de autorização devendo o utilizador aceder ao(s) documento(s) a partir de um endereço de IP da instituição detentora da supramencionada licença.

Ao utilizador é apenas permitido o descarregamento para uso pessoal, pelo que o emprego do(s) título(s) descarregado(s) para outro fim, designadamente comercial, carece de autorização do respetivo autor ou editor da obra.

Na medida em que todas as obras da UC Digitalis se encontram protegidas pelo Código do Direito de Autor e Direitos Conexos e demais legislação aplicável, toda a cópia, parcial ou total, deste documento, nos casos em que é legalmente admitida, deverá conter ou fazer-se acompanhar por este aviso. 

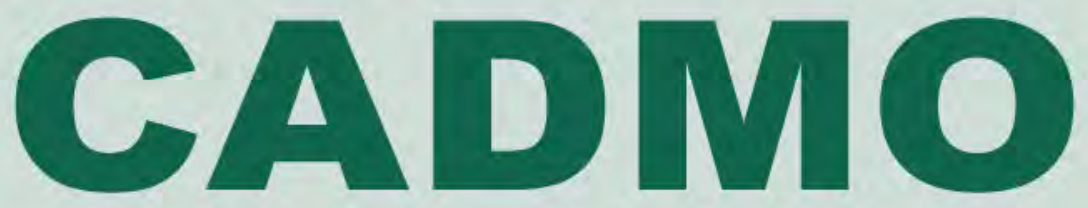

Revista de História Antiga

\author{
Centro de História \\ da Universidade de Lisboa
}

\title{
22
}

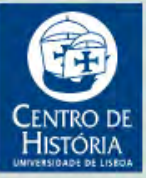

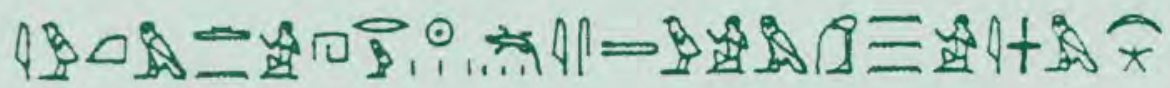

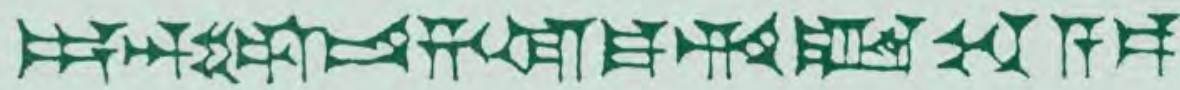
MHNIN AEI $\Delta \mathrm{E} \Theta \mathrm{EA} \Pi \mathrm{\Pi H} \Lambda \mathrm{HIA} \Delta \mathrm{E} \Omega$ 


\title{
O ACRÓSTICO DO TÚMULO DE KHERUEF
}

\author{
PAULO CARREIRA \\ Universidade de Lisboa \\ BorgesCarreira@sapo.pt
}

\section{Resumo}

Tem o presente trabalho como objectivo a tradução e exegese de um acróstico existente no túmulo do superintendente Kheruef (TT 192), o qual viveu na XVIII dinastia, durante o reinado de Amen-hotep III. Reflectindo o período de intenso labor filosófico e teológico que então se vivia, o texto sofreu a influência das correntes de pensamento predominantes, a saber:

- A unicidade amoniana, que fazia de Amon o novo demiurgo sob a sua forma ( $h p r)$ de Amon-Ré-Atum, mas que ao mesmo tempo o aproximava da humanidade como o «deus pessoal» de cada um.

- A nova teologia solar, designação de Jan Assmann para uma nova teoria para-científica e desmitologizada da vida na terra, explicada em termos do calor e da luz solar. Esta teoria é considerada uma das fontes principais das futuras doutrinas atonistas

A unicidade amoniana constitui a principal influência detectável no acróstico que aqui apresentamos, embora estejam igualmente presentes alguns princípios da nova teologia solar.

Palavras-chave: Kheruef: túmulos; funcionários; Amon; nova teologia solar

\begin{abstract}
The purpose of the present work is the translation and exegesis of an acrostic from the tomb of superintendent Kheruef (TT 192) who lived under the XVIII dynasty, reign of king Amenhotep III. Reflecting a time of intensive philosophical and theological labour, the texts were obviously influenced by contemporary teachings, namely:
\end{abstract}


- Amonian unicity, which considered the former teban god Amun as the new demiurge under his form ( $h p r)$ of Amun-Re-Atum and simultaneously made him close to humankind, a «personal god» to everyone.

- New solar theology, an Jan Assmann designation for a new para-scientific demythologized theory of life on earth as explained by solar heat and light. This theory is commonly considered to be one of the main sources of the future athenist doctrines.

Amonian Unicity proved to be a prime influence on the acrostic although some new solar theology principles can also be detected.

Key-words: Kheruef; tombs; royal officials; Amun; new solar theology

\section{Introdução}

Kheruef foi um distinto elemento do quadro de funcionários de Amenhotep III (c. 1402-1364 a. C.). Os textos gravados no túmulo dizem-nos que o seu nome de nascimento não seria este ${ }^{1}$; num deles aparece como

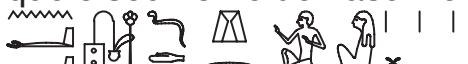

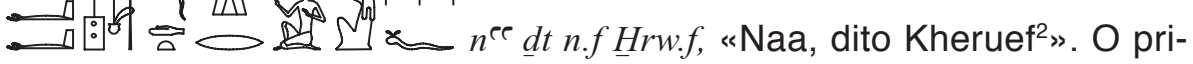
meiro nome pode traduzir-se como "O suave» e o segundo como "Os subalternos (são) dele». Era filho de Siked, que era escriba do exército do senhor das Duas Terras, e de Ruiu, «ornamento real, cantora de Ísis, mão do deus, cantora de Amon». Pertencia pois à classe dirigente, de acordo como o seu título de iri-pat hatiá (iry-pt ḩ3ty-`), «membro da elite e governador». Esteve particularmente ligado ao serviço da rainha Tié, desempenhando os cargos de imirá-per en hemet-nesu ueret (imy-r pr $n$ hmt-nswt wrt) «mordomo da casa da grande esposa real» e imirá-per en hemut-nesu ueret em per Amon (imy-r pr n hmt-nswt wrt m pr'Imn), «superintendente do património da grande esposa real na Casa de Amon», isto é, no domínio de Amon. Foi também imirá sedjautiu (imy-r sdibtyw), "superintendente dos tesoureiros» ou «tesoureiro-chefe», e ainda kherep ah en neb-Taui ( $h r p$ `h $n n b t 3 w y$ ), «grande administrador do palácio do senhor das Duas Terras».

Trabalhando directamente com o casal régio, foi encarregado da organização de dois jubileus. Daí que ele se apresente à posteridade como heri sechtá en per-nesu (hry sšt $n$ n pr nswt), ou seja, «o que estava nos segredos da casa do rei». Fez bem o seu trabalho e foi recompensado com o ouro que os soberanos distribuíam então pelos seus leais servidores 
e, tal como eles, usufruiu de um túmulo no chamado "Vale dos Nobres», actualmente designado por TT 192. Tal como é hábito entre os seus contemporâneos ${ }^{3}$, o túmulo de Kheruef ostenta uma grande quantidade de títulos honoríficos, como ser (sr), «funcionário», semer uati (smr w`ty), «amigo único», e de dignos epítetos que culminam com imakhi kher Amon (im3hy hr'Imn), «proclamado venerável por Amon». Isto não obsta a que a sua figura tenha sido martelada, talvez por iconoclastas atonianos.

A vida era bela para Kheruef e para os seus colegas que, certamente nos vagares das respectivas profissões, liam e compunham textos eruditos ou belos poemas de amor. Dois achados arqueológicos mostram que estes intrincados «jeux d'esprit» se estendiam para além da morte, constituindo talvez um desafio de carácter lúdico para os futuros visitantes. Efectivamente, na segunda sala do túmulo de Khaemhat ${ }^{4}$, que era imirá chenuti (imy-r šnwty), "superintendente do duplo celeiro ${ }^{5}$ », existe um texto criptográfico, e no túmulo de Kheruef, lado sul do corredor de entrada, foi mandado gravar um acróstico segundo uma matriz de treze linhas por catorze colunas.

A sua tradução e exegese constituem o objectivo deste trabalho.

\section{Envolvente religiosa}

A fim de tornar estes hinos mais compreensivos, importa fazer uma breve incursão nos domínios da situação religiosa que se vivia no tempo de Kheruef.

No decurso da XVIII dinastia, particularmente a partir do reinado de Hatchepsut, assistiu-se ao reforço de um movimento filosófico e teopolítico que se veio a traduzir na progressiva acumulação de poderes numa única entidade divina, Amon de Tebas. Isto foi interpretado por Assmann como o produto de uma crise do ancestral politeísmo egípcio ${ }^{6}$. Se, aparentemente, o politeísmo tradicional não parece estar em causa, nem há sinais de uma descrença generalizada, se os templos continuam a ser erguidos ou renovados ${ }^{7}$, não é menos verdade que há uma "crise», mais ou menos subterrânea, entre os intelectuais, a qual explodirá, embora de forma limitada, com Amen-hotep IV / Akhenaton ${ }^{8}$.

De facto, o que os documentos nos mostram é a formação de dois poderosos grupos que se vão afrontar primeiramente a nível religioso e posteriormente a nível político. O primeiro destes grupos engloba, muito 
provavelmente, o soberano e seus funcionários próximos e está ligado à manutenção e reforço do poder real, o segundo é constituído pelo clero de Amon, sediado em Tebas-Uaset e pretende a expansão e fortalecimento do poder sacerdotal.

Inicialmente deus de Tebas-Uaset, com alguma expressão no Império Médio ${ }^{9}$, Amon fora tomado como o patrono da vitória egípcia sobre os Hicsos e impulsionador da política de expansão dos reis do Império Novo. Acompanhando este movimento, o seu clero elaborou progressivamente um programa teológico, que denominaremos unicidade amoniana ${ }^{10}$, e que a documentação existente mostra haver-se desenvolvido de acordo com os seguintes pontos:

1 - Atribuição de um papel demiúrgico a Amon, sincretizando-o com os demiurgos ancestrais, Atum e Ré.

2 - Concessão dos títulos de nesu-netjeru (nsw-ntrw), «rei dos deuses», e nesu-biti (nsw-bity), «rei do Alto e do Baixo Egipto», à nova entidade Amon-Ré.

3 - Leitura e apresentação de outros deuses como suas kheperu (hprw), «manifestações».

4 - Aproximação do primitivamente distante Amon ao comum dos mortais, tornando-o num deus cujos ouvidos talhados na pedra escutavam as tragédias físicas e morais que sempre acompanharam o ser humano. Na prática, isto correspondia à usurpação do papel de administrador da justiça que sempre havia cabido ao rei.

Cada um destes pontos teve consequências ideológicas, e principalmente políticas. A relação entre o sumo sacerdote do «rei dos deuses» e o soberano, que é um Hórus vivo, torna-se desequilibrada, nomeadamente sempre que o deus Amon é solicitado para o designar publicamente, como aconteceu com o jovem Tutmés III e logo a seguir com sua tia Hatchepsut. Compreende-se portanto que Tutmés IV tenha optado por receber a coroa de Ré-Horemakhet, a Esfinge de Guiza, e não de Amon.

Paralelamente a este movimento de unificação amoniana, assiste-se a uma reinterpretação para-científica e desmitologizada da ordem do mundo, conhecida por «nova teologia solar». Esta mergulha as suas raízes no pensamento religioso solar que tinha sido implementado na IV dinastia e transparece, por exemplo, na XVIII dinastia nos hinos do túmulo de Suti e Hor. Contrariamente aos antigos mitos sobre a sua acidentada viagem 
e o combate diário contra as forças do caos, o Sol torna-se a força motriz de uma cadeia de causas e efeitos: fonte da luz e do calor que fazem crescer as plantas, os animais e os seres humanos. Simultaneamente longínquo e próximo, é ele a explicação última do mecanismo da visão, o regente do dia e da noite, das estações e da grande inundação do rio Nilo. Afadiga-se, quotidianamente, com a gestão do mundo mas o seu percurso nocturno é secreto.

Em si mesma, esta nova teologia solar não é um obstáculo ao que designámos por unicidade amoniana. Efectivamente, o disco ou globo solar, Aton, é sempre considerado a hipóstase de um deus e nunca um deus por direito próprio. Para o clero tebano, quem vive em Aton é, evidentemente, Amon-Ré, mas nada impede que seja Ré ou Ré-Horakhti, de acordo com as doutrinas atonistas ${ }^{11}$. Esta ambiguidade da nova teologia solar permitiu-lhe atravessar incólume o período amarniano e prosseguir, pelo menos até ao fim dos Ramséssidas, mesmo que muito do seu discurso tenha sido aproveitado por Akhenaton e seus partidários.

\section{0 texto}

A fonte utilizada no presente trabalho foi a reconstituição textual de Wente ${ }^{12}$. Estamos perante um conjunto de dois hinos, um de leitura segundo as linhas, texto horizontal $(\mathrm{H})$, e outro de texto vertical $(\mathrm{V})$, de leitura segundo as colunas. Daí o seguinte esquema de numeração:

\begin{tabular}{|l|l|l|l|l|l|}
\hline & A & B & C & $\ldots$ & J \\
\hline 1 & & & & & \\
\hline 2 & & & & & \\
\hline$\ldots$ & & & & & \\
\hline 13 & & & & & \\
\hline
\end{tabular}

\section{Linha 1}

1

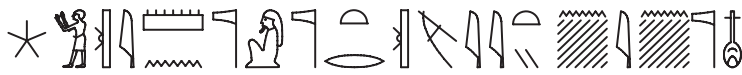

$d w$ 'Imn ntr $n \underline{t r}(y) \operatorname{mr}(w)$ ty $n \ldots$ in ... ntr $n f r$

Adoração a Amon, ser divino ${ }^{13}$, o bem-amado de $^{14} \ldots$ pelo deus beneficente 
2

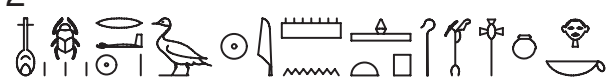

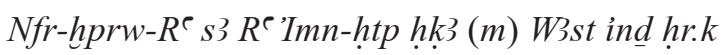

Neferkheperuré, filho de Ré, Amen-hotep, governante de Tebas. Saudações a ti ${ }^{15}$

\section{Linha 2}

3

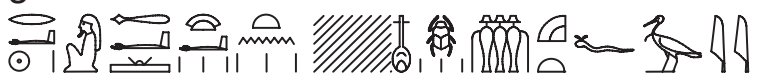

$R^{\top}{ }^{\top} h^{\ulcorner} w(. t n) \ldots n f r(w)$ hprw hnt itrt.f b3y

ó Ré, grande nas (tuas) aparições, de belas formas, o que está diante do seu santuário, o do ba,

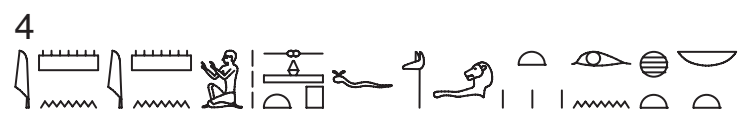

Imn imnw shtp.f wsr h3wt iri.n ht nbt

o mais oculto dos ocultos quando repousa, de semblante poderoso ${ }^{16}$, ele fez todas as coisas ${ }^{17}$.

\section{Linha 3}

5

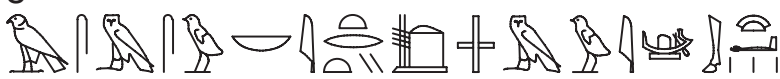

Hr smsw nb itrty ${ }^{18}$ imy wis whm hriw

Hórus mais velho, senhor dos dois conclaves ${ }^{19}$, o que está na barca ${ }^{20}$ sagrada, repetindo aparições

6

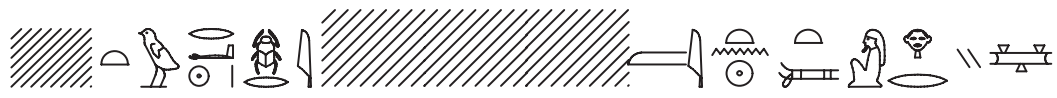

...tw Re-hpry......... m'Itn'Itm hry

... Ré-Khepri ......... como o disco solar. Atum que está sobre

\section{Linha 4}

7

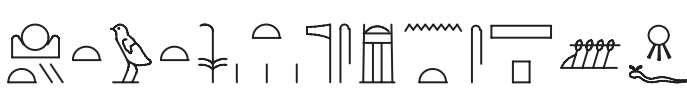

3hty twt nsw ntrw sitrt nt šsp.f 
os dois horizontes, perfeito, rei dos deuses, que faz avançar a sua luz do $\operatorname{dia}^{21} \ldots$

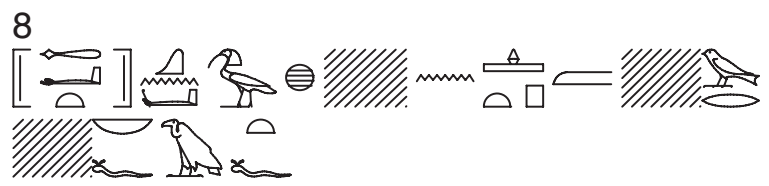

$3 \mathrm{kn}(\mathrm{t}) 3 \mathrm{~h} \ldots \mathrm{nhtp} \mathrm{m} \ldots \mathrm{wr}$...nb.fmwt.f

(grande) em valor, beneficente...pacífico em... grande ....seu senhor e (de) sua mãe

\section{Linha 5}

9

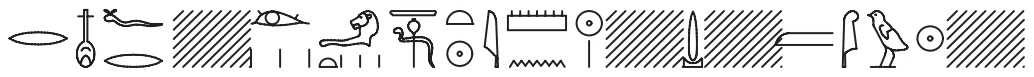

$r n f r \ldots r s h 3 w t t^{\complement} h \underline{d}{ }^{\prime} I m n-R^{\ulcorner} \ldots \ldots(w d j ?) \ldots m \check{s} w$

Orador $^{22}$ perfeito... de ar vigilante ${ }^{23}$ quando a terra resplandece, AmonRé... (prosperidade ?) ${ }^{24}$... como a luz...

10

?

$h k 3$ Wist... hnt...M3nw htpy(w)

Soberano de Uaset (Tebas) ...o que está à frente de ... Manu ${ }^{25}$ o mais gracioso

\section{Linha 6}

11

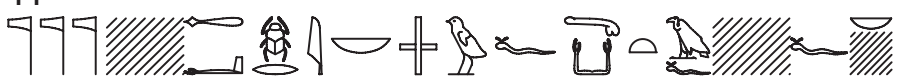

ntrw... 3 hpry nb imiw.f K3 mwt.f... f...nb...

dos deuses ${ }^{26}$, o grande que veio à existência, senhor dos que estão com ele, Kamutef ${ }^{27}$... senhor ...

12

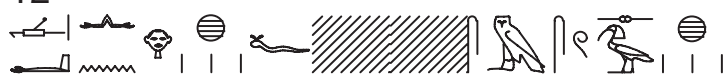

w`nn hr hww. f.... smsw s3hw

único, não há ninguém para além dele... o mais velho dos que foram proclamados $a k h u^{28}$ 


\section{Linha 7}

13

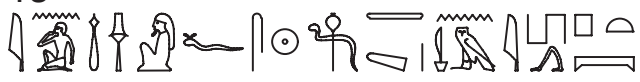

in.i ${ }^{3}$ shm.f shd $t^{\ulcorner}$nmi.pt

Eu digo ${ }^{29}$ : É aquele deus cujo poder é grande, que ilumina a terra, que atravessa ${ }^{30} \mathrm{o}$ céu,

14

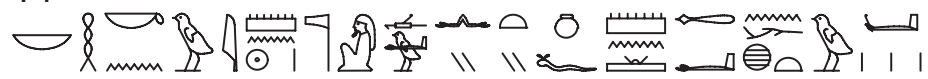

$n b$ h hknw'Imn-R ntr $^{\top} w^{\top} w$ nn iwty $n w$. f mn 3 nhtw

o senhor do júbilo ${ }^{31}$, Amon-Ré, deus único e sem par, estável ${ }^{32}$ e grande em força ${ }^{33}$

15

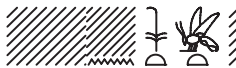

......n nsw bit(y) ...

... do (?) rei do Alto e do Baixo Egipto...

\section{Linha 8}

16

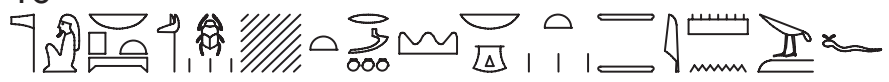

ntr nb pt wsr hprw ...t r M3nw nb nswt t3wy imn sšm.f

deus e senhor do céu, poderoso em manifestações, ... porta-voz de Manu, senhor dos tronos das Duas Terras ${ }^{34}$, os seus desígnios são ocultos.

17

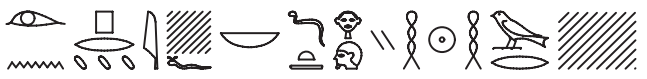

iri.n.ff) (n)pri ... f fnb $\underline{d} t$ hry-tp nhh wr...

Ele fez o cereal, ..., senhor da eternidade e garante da continuidade, o grande...

\section{Linha 9}

18

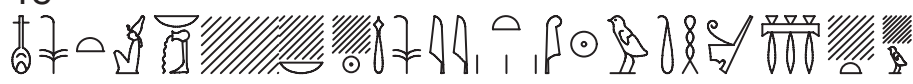

fr nsw $n b w^{c} b \ldots \ldots n b \ldots$... 3 nsywt šw thnt ...t ...w

rei perfeito, senhor puro, ... grande em soberania, luz do Sol, brilhante... 
১.

Imn-R ...(nb) t3wy ...

Amon-Ré... (senhor das) Duas Terras ...

\section{Linha 10}

19

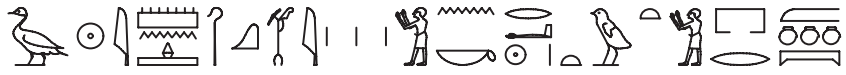

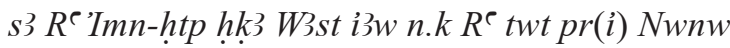

Filho de Ré, Amen-hotep, soberano de Uaset (Tebas); louvor a ti Ré, imagem divina que saiu do Nun

20

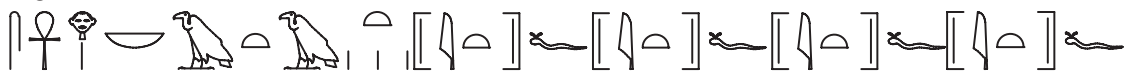

$\check{s}\ulcorner h h$ hr nb mwt mwtw it itw

e que a todos faz viver, mãe das mães e pai dos pais ${ }^{35}$

21

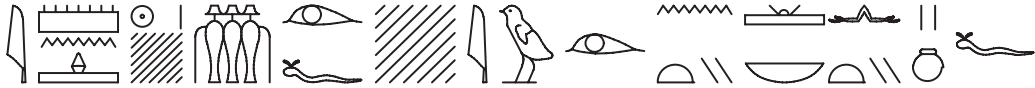

'Imn-htp Re ...hnt ir(.n).f ... iw iri nty nb iwty sn-nw.f

Amen-hotep, Ré ..., o que está à frente de tudo o que fez, não há outro como ele.

22

๑

hi $i$ hr-tp t3 $h^{\top} w . f^{\prime} I t n \ldots t s \ldots \ldots f \ldots$

Quando aparece sobre a terra, o seu corpo é o disco solar... que une......

\section{Linha 12}

23

$\left\{\Delta^{\uparrow}{ }^{\mathfrak{Y}}\right.$

$h k 3$ Wist ......nb.....

Governante de Uaset (Tebas)... ... senhor... ...

24

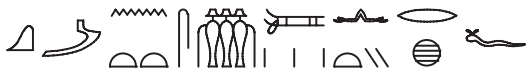

km(3) ntt s shnt tmw iwty rh.f 
que criaste (tudo) o que existe, que tudo fazes avançar, (que és) incognoscível

25

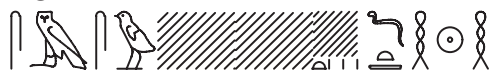

smsw ........tw $\underline{d} t n h h$

o mais velho, ....... eternamente e para sempre.

\section{Linha 13}

26

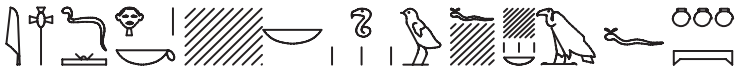

ind hr.k...nb nrw.f ...w nb mwt.f Nwnw

Louvor a ti, senhor do terror, ... a sua mãe é Nun.

27

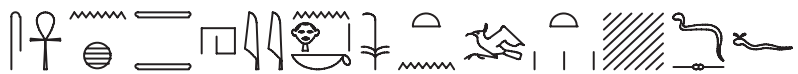

$\check{s}$ `nh t3wy hy $n$ hr.k nsw rhyt... ds.f

Ele faz viver as Duas Terras. Louvor à tua face, rei da humanidade... ele próprio.

28

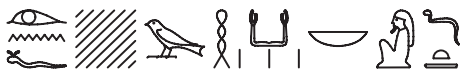

ir.n.f... wr hkjw nb $\underline{d} t$

Ele fez... grande em magias ${ }^{36}$, divino senhor da eternidade.

\section{Texto vertical}

\section{Coluna A}

1

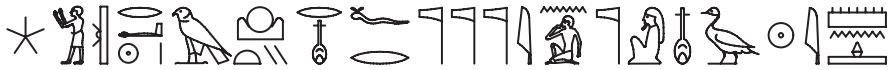

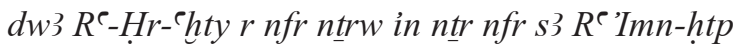

Adoração a Ré-Horakhti, boca perfeita dos deuses, diz o deus perfeito, o filho de Ré, Amen-hotep,

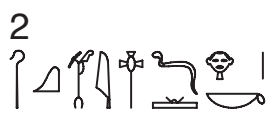

$h k 3 W^{2}$ st ind $h r . k$

soberano de Uaset (Tebas). Louvor a ti 


\section{Coluna B}

3

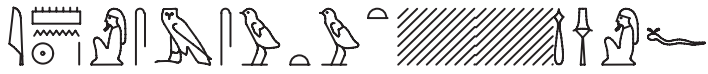

Imn-R` smsw twt ...... 3 shm.f

Amon-Ré, o mais velho, perfeito. ...... grande é o seu poder

4

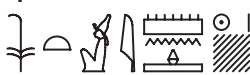

nsw'Imn-http $R^{\ulcorner} \ldots$

Rei Amen-hotep, sol ...

Coluna C

5

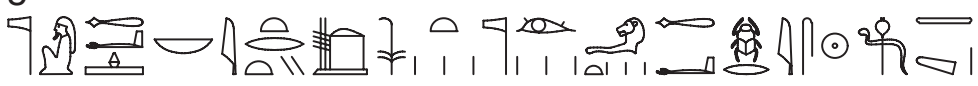

ntr 9 nb itrty nsw ntrw rs h3wt 3 hpry shd $t 3$

deus grande, senhor dos dois conclaves, rei dos deuses, de ar vigilante, o grande que veio à existência, que ilumina a terra,

6

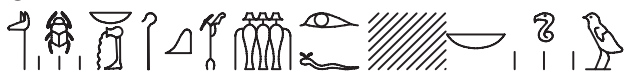

wsr hprw nb w'b hkj W3st hnt(y) iri.f ...nb nrw

rico em manifestações, senhor puro, soberano de Tebas, o que está à frente da sua criação, ... senhor do terror

\section{Coluna D}

7

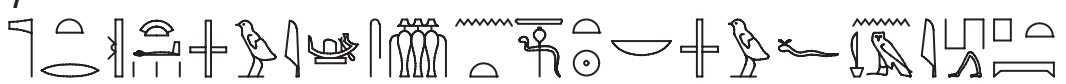

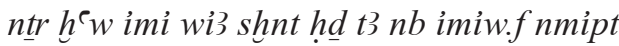

divino em aparições. O que está na barca e que faz avançar a aurora, o senhor dos que estão com ele, que atravessa o céu,

8

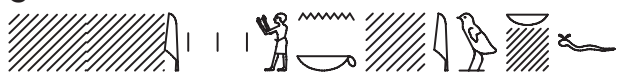

........i isw n.k...iw nb...f

$\ldots \ldots$.... louvor a ti... tu és o senhor de ... 


\section{Coluna E}

9

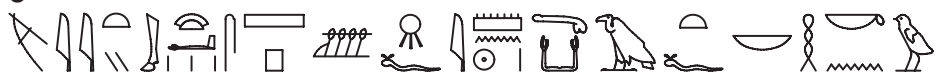

$m r(w) t y$ whm ḩ3w sšp.f'Imn $R^{\ulcorner} K 3$ mwt.f nb ḥknw

o bem amado, (o que) repete aparições, a luz do dia é sua, Amon-RéKamutef, senhor do júbilo.

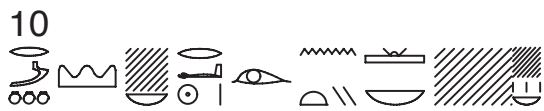

$r M 3 n w \ldots n b R^{e}$ iri nty $n b \ldots n b w$

Porta-voz de Manu... tudo, Ré que fez todo o ... e tudo o que existe

Coluna F

11

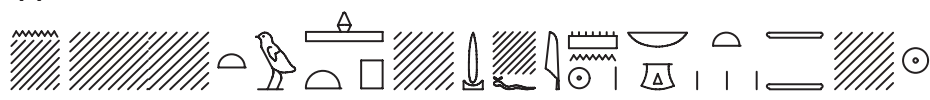

$n$......tw htp...d...f. f'Imn-Re nb nswt t3wy ...

de .... se apazigua ... Amon-Ré, senhor dos tronos das Duas Terras ...

12

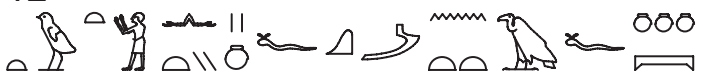

twt ỉw (.i) iwty sn-nw.f km(3) ntt mwt.f Nwnw

Louvo a (sua) imagem, não há segundo como ele que criou ${ }^{37}$ tudo o que existe, a sua mãe é Nun.

\section{Coluna G}

13

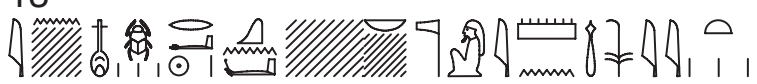

in(.f)Nfrhprw-R` kni ...nb...ntrimn 3 nsywt

Assim diz Neferkheperuré, o forte, senhor... deus oculto, grande em soberania

14

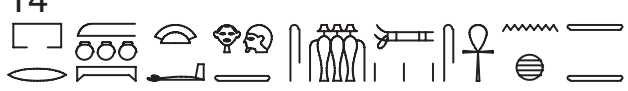

pri Nwnw hri hr-tp t? shn tmw s'nh t3wy

que saiu do Nun e aparece(u) sobre a terra. Ele faz avançar todos os homens, ele dá vida às Duas Terras. 


\section{Coluna H}

15

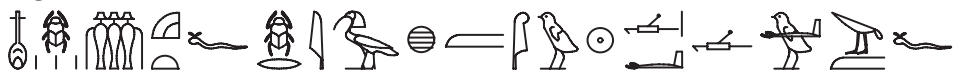

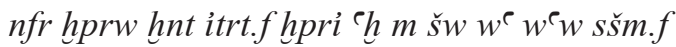

Belo (nas suas) manifestações, o que está diante do seu santuário, Khepri, benéfico na luz do Sol, único dos únicos, ele fez-se a si mesmo,

16

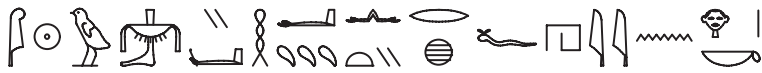

šw nbi hִw.f iwty rh.f hy $n$ hr.k

luz dourada é o seu corpo, ele é incognoscível. Louvor a ti

\section{Coluna I}

\section{7}

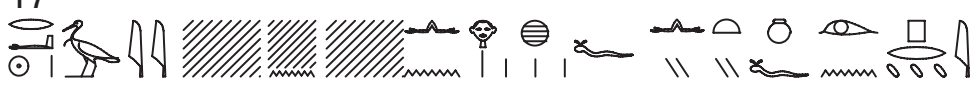

$R^{\top}$ b3y .......n ...nn hr ḩ3w.f iwty nw.f iri.n pri

Ré (o dotado de) ba... o sem par, não há outro como ele. Ele fez o cereal.

18

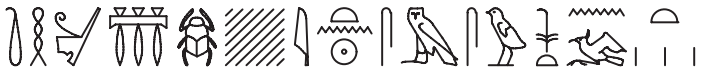

thn hpr(w) ...'Itn smsw nsw rhyt

Brilhante de formas ... o disco solar, o mais velho, rei da humanidade,

Coluna J

19

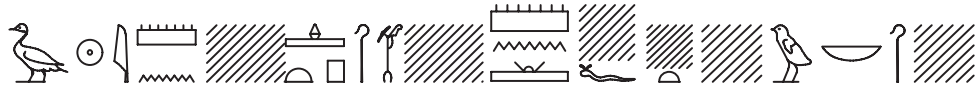

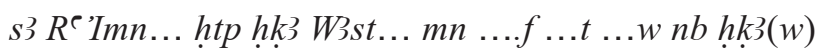

O filho de Ré, Amen-hotep, governante de Tebas... estável... senhor dos governantes

20

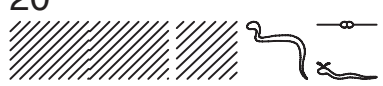

$\ldots \ldots . . . d s . f$

... ... ... ele próprio. 


\section{Coluna K}

21

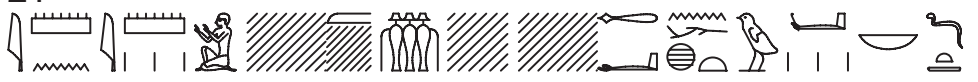

Imn imnw ... m... hnt...... 3 nhtw $n b \underline{d} t$

O mais oculto dos ocultos... o que está à frente de ... grande em força, senhor da eternidade

22

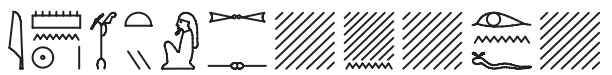

Imn-Re W3sty ts.....n ... ir.n.f

Amon-Ré, o tebano que junta ... ele fez...

\section{Coluna L}

23

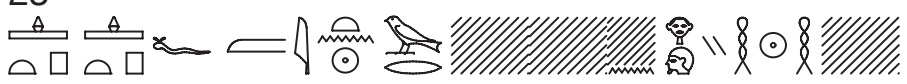

htp htp.f m 'Itn .........n n hry-tp (n)hh

gracioso, quando repousa como o disco solar, grande... ...o garante da continuidade.

24

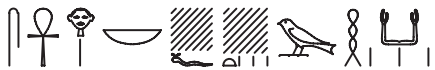

$\check{s} \lessdot n h$ hr $n b . . f$..tw wr hkjw

Que tudo faz viver ... grande em magias

\section{Coluna M}

\section{5}

ใ

hkj W3st wsr ḩ3 tm ...f..nb.f M3nw smsw nsw-bit(y) wr ...t3wy

Soberano de Tebas de poderoso semblante, Atum ... Manu, o mais velho, Rei do Alto e do Baixo Egipto, grande ... (senhor) das Duas Terras

26

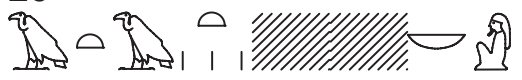

$m w t m w w t \ldots \ldots n b$

Mãe das mães... senhor divino 


\section{Coluna $\mathbf{N}$}

27

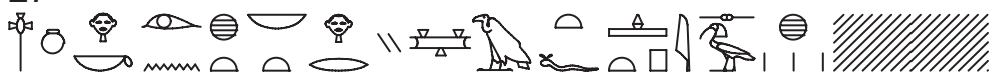

ind hr.k iri.n.ht nbt hry mwt.f htpi sihww ......

saudações a ti, que fizeste todas as coisas, o que é superior a sua mãe ${ }^{38}$, o mais gracioso dos que foram declarados akhu

28

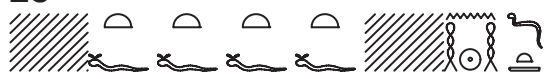

(i) $t$ (i)tw ... nhẹh $\underline{d} t$

Pai dos pais... para sempre e eternamente.

\section{Análise textual}

Cada um dos textos foi examinado de acordo com uma grelha de leitura em nove pontos, quadros I a IX, tal como se mostra seguidamente.

O destinatário destes hinos é evidentemente Amon-Ré (quadro I), como é referido cinco vezes nos dois hinos. Manifesta-se sob várias formas (quadro II):

Quadro I - Referente divino dos dois textos

\begin{tabular}{|l|l|l|}
\hline Referente divino & Texto H & Texto V \\
\hline Amon-Ré & 7,$14 ; 8,19$ & B 3; F 34; K 50 \\
\hline Total & 2 & 3 \\
\hline
\end{tabular}

Quadro II - Manifestações divinas de Amon-Ré

\begin{tabular}{|l|l|l|}
\hline Manifestações divinas & Texto H & Texto V \\
\hline Hórus & 3,5 & \\
\hline Kamutef & 6,11 & \\
\hline Ré-Horakhti & & A 1 \\
\hline Amon-Ré-Kamutef & & E 9 \\
\hline Ré-Khepri & 5,6 & \\
\hline Khepri & & H 15 \\
\hline Ré & 2,3 & \\
\hline Atum & 5,6 & E 10 \\
\hline Amon & 1,11 & \\
\hline Total & 6 & 4 \\
\hline
\end{tabular}


Associado a Ré, Amon recebeu as kheperu (hprw), «manifestações» do velho deus: nasce sob a forma do escaravelho Khepri, atinge o máximo da sua força ao meio-dia solar, afirmando-se especificamente como Ré, e chega ao ocaso sob a forma de Atum, que na antiga concepção heliopolitana tinha gerado a Enéade. Tendo alcançado o domínio dos dois pontos principais do circuito solar, Amon é igualmente manifesto como Ré-Horakhti e, mergulhando nos primórdios da religião egípcia, é também o velho Hórus, o Antigo, que se adorava em Behedet-Edfu, e cujo emblema se encontra nos pórticos dos pilones dos templos, sob a forma de um disco solar alado e defendido por duas serpentes.

Mas Amon usufrui também de prerrogativas mínicas, pois é Kamutef, «o touro de sua mãe», e salienta novamente a sua potência criadora sob o nome de «o touro que está em Heliópolis», de acordo com o início do capítulo 15 do «Livro dos Mortos» ${ }^{39}$ e no Grande Hino a Amon, do Cairo ${ }^{40}$. Sem perda do seu papel de «rei dos deuses», Amon-Ré conserva o carácter misterioso inerente a Amon, mas torna-se visível em Aton ${ }^{41}$, «o disco solar», sua hipóstase, que navega pelo céu (quadro III), tal como se manifesta fisicamente na imagem que se desloca na barca, aos ombros dos sacerdotes, durante as grandes festas. Apesar de tal majestade, ainda está próximo dos fiéis, pois os seus ouvidos, representados na pedra dos templos e em estelas (estelas das orelhas), escutam todos os necessitados.

Quadro III - Manifestações de Amon-Ré, no mundo físico

\begin{tabular}{|c|c|c|}
\hline Manifestações no mundo físico & Texto H & Texto V \\
\hline$h^{\ulcorner} w . f^{\prime} I t n$, «o seu corpo é o disco solar» & 10,22 & I 18 \\
\hline šw nby $h^{\ulcorner} w . f$, «a luz dourada é o seu corpo» & 9,18 & H 16 \\
\hline nmi pt, «atravessa o céu» & 7,13 & D 7 \\
\hline htp.f m 'Itn, «repousa no disco solar» & & L 23 \\
\hline $\begin{array}{l}\text { shnt hִd } t 3 \text {, «faz avançar a aurora» } \\
\text { stirt nt šsp.f, «faz avançar a sua luz do dia» }\end{array}$ & 4,7 & D 7 \\
\hline Total & 4 & 5 \\
\hline
\end{tabular}

Amon fora já considerado um dos oito princípios criadores da cosmogonia de Hermópolis (onde formava um casal com a sua paredra prosódica Amonet), mas ao ser associado a Atum-Ré de Heliópolis passou a ser o princípio único, o demiurgo, que, por definição, se faz a si mesmo (quadro IV). 
Quadro IV - Filiação de Amon-Ré

\begin{tabular}{|c|c|c|}
\hline Filiação & Texto H & Texto V \\
\hline $\begin{array}{l}\operatorname{pr(i)} N w n w, \text { «saiu de Nun» } \\
m w t . f N w n u, \text { «sua mãe é Nun» }\end{array}$ & $\begin{array}{l}10,19 \\
13,26\end{array}$ & F 12 \\
\hline hry mwt.f, «o que é superior a sua mãe» & & N 27 \\
\hline$s \check{m} m . f$, «fez-se a si mesmo» & & H 15 \\
\hline 3 hpry, «o grande que veio à existência» & 6,11 & \\
\hline Total & 3 & 3 \\
\hline
\end{tabular}

Mantendo a velha cosmogonia solar, Amon-Ré saiu de Nun ${ }^{42}$, um meio aquoso, tal como o bebé deixa o útero de sua mãe. Porque é uma entidade ordenada, maética, contrastando com o caos de onde se ergueu, pode dizer-se que «é superior a sua mãe». Contrariamente ao que acontece no Hino de Suti e Hor ${ }^{43}$ nunca é referida no acróstico a filiação à deusa Nut, teologização da abóbada celeste.

$\mathrm{Na}$ sua qualidade de deus supremo, são-lhe outorgados títulos que aludem a essa especificidade (quadro V): é um soberano absoluto, dirige as assembleias dos deuses do Alto e do Baixo Egipto, domina 0 tempo, pode mesmo ser terrível, tal como o faraó que se bate como um leão ${ }^{44}$. Paralelamente, e isto vai fazer toda a diferença, ele é o senhor da alegria, como é visível na sua bela festa de Opet, e é um pai e uma mãe não só para o rei do Egipto mas para todos os seus habitantes, ouve-os e aconselha-os com os seus oráculos.

\section{Quadro V - Títulos divinos de Amon-Ré}

\begin{tabular}{|c|c|c|}
\hline Títulos divinos & Texto H & Texto V \\
\hline$n \underline{t} r$ ntr $(y)$, «ser divino» & 1,1 & \\
\hline 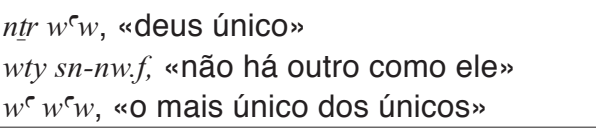 & $\begin{array}{l}6,12 \\
7,14 \\
10,21\end{array}$ & H 15 \\
\hline$n t r n b p t$, «deus e senhor do céu» & 8,16 & \\
\hline $\begin{array}{l}\underline{t w} \text { t } n s w \text { ntrw, «imagem do rei dos deuses» } \\
n s w n \underline{t r} w, \text { «rei dos deuses» }\end{array}$ & 4,7 & $\begin{array}{l}\text { B } 3 \\
\text { C } 5\end{array}$ \\
\hline nb itrty, «senhor dos dois conclaves» & 3,5 & C 5 \\
\hline $\begin{array}{l}n b \underline{d} t, \text { «senhor da eternidade» } \\
h r y \text {-tp (n)hh, «garante da continuidade }\end{array}$ & 13,28 & L 23 \\
\hline$n b w^{c} b$, «senhor puro» & & C 6 \\
\hline $\begin{array}{l}n b n r w, \text { senhor do terror» } \\
n b n r w . f, \text { «senhor do seu terror» }\end{array}$ & 13,26 & C 6 \\
\hline$n b n h k n w$, «senhor do júbilo» & 7,14 & E 9 \\
\hline
\end{tabular}




\begin{tabular}{|c|c|c|}
\hline Títulos divinos & Texto $\mathrm{H}$ & Texto V \\
\hline$r$ M3nw, «porta-voz de Manu & 8,16 & E 10 \\
\hline$m w t$ mwwt, «mãe das mães» & 10,20 & M 26 \\
\hline it itw, «pai dos pais» & 10,20 & N 28 \\
\hline Total & 12 & 11 \\
\hline
\end{tabular}

Como todos os grandes deuses do panteão, também o poderoso Amon-Ré usufrui de numerosos epítetos (quadro VI):

\section{Quadro VI - Epítetos divinos de Amon-Ré}

\begin{tabular}{|c|c|c|}
\hline Epítetos divinos & Texto H & Texto V \\
\hline hnt itrt.f, «o que está diante do seu santuário» & 2,3 & H 15 \\
\hline hnty irf. , «o que está diante da sua criação» & 10,21 & C 6 \\
\hline imy wỉ, «o que está na barca» & 3,5 & \\
\hline 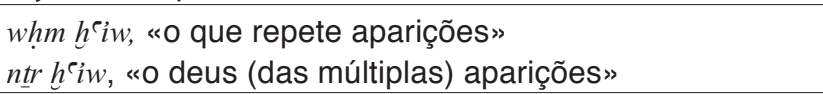 & 3,5 & $\begin{array}{l}\text { E } 9 \\
\text { D } 7\end{array}$ \\
\hline $\begin{array}{l}\text { wsr hprw, «poderoso (nas suas) manifestações» } \\
\text { nfr hhprw, «belo (nas suas) manifestações» }\end{array}$ & $\begin{array}{ll}8,16 \\
2,3 \\
\end{array}$ & $\begin{array}{l}\text { C } 6 \\
\mathrm{H} 15\end{array}$ \\
\hline $\begin{array}{l}\text { imn imnw, «o mais oculto dos ocultos» } \\
\text { imn sšm.f, «os seus desígnios são ocultos» } \\
\text { iwty rh.f, «ele é incognoscível» } \\
\text { ntr imn, «deus oculto» }\end{array}$ & \begin{tabular}{|l|}
2,4 \\
8,16 \\
12,24
\end{tabular} & $\begin{array}{l}\text { K } 16 \\
\text { H16 } \\
\text { G13 }\end{array}$ \\
\hline $\begin{array}{l}b 3 y, \text { «o do ba» } \\
R^{\complement} b 3 y, \text { Ré, dotado de ba» }\end{array}$ & 2,3 & 117 \\
\hline$r s h 3 w t$, «de ar vigilante» & 5,9 & C 5 \\
\hline$w s r h 3 w t$, «de semblante poderoso» & 2,4 & \\
\hline mrwty, «bem amado» & 1,1 & E 9 \\
\hline$h t p$, «pacífico» & 4,8 & \\
\hline$h t p y(w) n t r w, ~ « 0$ mais gracioso dos deuses» & $\begin{array}{l}5,10 \\
6,11\end{array}$ & \\
\hline$w s r h k 3 w$, «grande em magias» & 3,28 & \\
\hline$s m s w$, «o mais velho» & & I 8; M 25 \\
\hline $\begin{array}{l}\text { šmsw s3hw, «o mais velho dos que foram declarados akhu» } \\
h t p i s 3 h w \text {, «o mais velho dos que foram declarados akhu» }\end{array}$ & 6,12 & N 27 \\
\hline Total & 18 & 16 \\
\hline
\end{tabular}

Todos os deuses, e portanto Amon-Ré, eram adstritos a determinadas funcionalidades (quadro VII) mas, na sua qualidade de demiurgo, ele domina-as todas, é o criador da vida, um «criador continuado» porque todas 
as vidas são breves. A sua driving-force está bem explicitada nos hinos: é a luz do Sol que ilumina a terra e permite que ela floresça em vida e alimento.

\section{Quadro VII - Funcionalidades de Amon-Ré}

\begin{tabular}{|c|c|c|}
\hline Funcionalidades & Texto H & Texto V \\
\hline $\begin{array}{l}\text { ir } n \text { ht } n b t, \text { «ele fez todas as coisas» } \\
k m 3 n t t, \text { «ele fez tudo o que existe» } \\
R^{\ulcorner} \text {ir } n t y n b . . n b w, \text { «Ré que fez todo o ... e tudo o que existe }\end{array}$ & $\begin{array}{l}2,4 \\
12,24\end{array}$ & $\begin{array}{l}F 12 \\
\text { E } 10\end{array}$ \\
\hline$s h d t 3, \ll i l u m i n a$ a Terra» & 7,13 & C 5 \\
\hline Ch $m \check{s} w$, «ele é benéfico na luz do Sol» & & H 15 \\
\hline$s^{e} n h h r n b$, «ele tudo faz viver» & 10,20 & L 24 \\
\hline$s^{\top} n h$ t $3 w y$, «ele dá vida às Duas Terras» & 13,27 & G 14 \\
\hline ir $n$ pri, «ele fez o cereal» & 8,17 & I 17 \\
\hline Total & 6 & 7 \\
\hline
\end{tabular}

Por todas as belas acções que realiza quotidianamente em prol da humanidade, Amon-Ré procede como um rei, rei de toda a humanidade e não só do Egipto, cuja titulatura básica ostenta (quadro VIII), frisando assim, tal como um soberano da XVIII dinastia, que é ele quem governa a cidade de Tebas.

Quadro VIII - Títulos reais de Amon-Ré

\begin{tabular}{|l|l|l|}
\hline Títulos reais & Texto H & Texto V \\
\hline$n s w$ rhyt, «rei dos povos, da humanidade» & 13,27 & $\mathrm{I} 18$ \\
\hline$n s w$ bit $(y)$, «Rei do Alto e do Baixo Egipto» & 7,15 & $\mathrm{M} 25$ \\
\hline$n b$ nswt $t$ 3wy, «senhor (dos tronos) das Duas Terras» & 8,16 & \\
\hline$h k$ W Wst, «governante de Tebas» & $\begin{array}{l}5,10 ; \\
12,23\end{array}$ & $\mathrm{C} 6$ \\
\hline Total & 5 & 3 \\
\hline
\end{tabular}

O principal epíteto real de Amon-Ré é evidentemente netjer-nefer (ntrr-nfr), «deus perfeito» ou «deus beneficente», o qual desde há gerações fazia parte do protocolo dos soberanos das Duas Terras. No entanto é possível reconhecer outros epítetos constantes destes hinos (quadro IX) em textos que se referem a reis. Akhenaton, por exemplo ${ }^{46}$.

Quadro IX - Epítetos reais de Amon-Ré

\begin{tabular}{|l|l|l|}
\hline Epítetos reais & Texto H & Texto V \\
\hline$m n$, «estável» & 7,14 & \\
\hline$n b h k 3 w$, «senhor dos governantes» & & $\mathrm{J} 19$ \\
\hline 3 $n h t w$, «grande em força» & 7,14 & \\
\hline
\end{tabular}




\begin{tabular}{|l|l|l|}
\hline 3 knt, «grande em valor» & 4,8 & \\
\hline ア nsywt, «grande em soberania» & & $\mathrm{G} 13$ \\
\hline $\begin{array}{l}\text { shntì tmw, «favorece a todos os homens, faz avançar a } \\
\text { humanidade» }\end{array}$ & $\mathrm{G} 14$ \\
\hline Total & 3 & 3 \\
\hline
\end{tabular}

\section{Conclusões}

De acordo com a grelha de leitura que foi utilizada, os dois hinos a Amon-Ré que constam do acróstico ${ }^{46}$ do túmulo de Kheruef podem ser considerados como homogéneos, já que a diferença entre o número total de itens por categoria, em cada um deles, é nula ou muito pequena.

$O$ deus solar é simultaneamente apresentado como rei dos homens e rei dos deuses e como tal dispõe de cerimoniosos protocolos abundantemente providos de epítetos. Se os compararmos com o Grande Hino a Amon, do Cairo (GHAC) e o Hino da estela de Suti e Hor $(\mathrm{HSH})^{48}$ dois textos coetâneos, verifica-se imediatamente que este último e o acróstico não se referem à luta nocturna do deus solar contra o monstro Apópis, que ele vence, permitindo assim o nascer do novo dia. Se, de acordo com Assmann ${ }^{49}$, este episódio está ausente da nova teologia solar (NTS), então os dois textos poderiam ser englobados nesta corrente filosófica mas não o Grande Hino. Na verdade as coisas são mais complexas.

O referente divino, Amon-Ré, vem descrito de uma forma antropomórfica como «jovem rapaz, belo de amor» (GHAC, linhas 20,21), zoomórfica como «grande falcão de peito ornamentado» (GHAC, linha 201; HSH, linha 35) ou astronómica, tal como na NTS. Aton é, então, chamado Aton en heru ('Itn $n h r w)$, «o disco solar de cada dia» ( $\mathrm{HSH}$, linha 33). Esta identificação é menos categórica no Grande Hino, onde ele é «senhor dos raios que faz a luz (...), ele estende sempre os braços àquele que ele ama (...), único, de braços numerosos» (GHAC, linhas $58 ; 60 ; 125)$, mas tão sugestiva como uma representação de Aton. O acróstico opta claramente por uma descrição astronómica simples e rigorosa: $\underline{h}^{\top} i \underline{h} r-t p t 3 h^{\complement} w$. f'Itn, «quando aparece sobre a terra, o seu corpo é o disco solar» (Acr. 10,22).

$\mathrm{Na}$ estela, o sol «deita-se no horizonte de Manu», no hino «ele passa a noite a vigiar a humanidade adormecida» (GHAC, linha 126) e é só aqui que encontramos uma profissão de fé em Amon, tão típica da piedade pessoal: escuta os aflitos, protege os humildes e o seu coração é benevolente 
(GHAC, linhas 71-75). No acróstico ele «repousa» (Acr. 2,4). Simplesmente, sem efectuar nenhum trabalho e sem combater nenhuma força maligna.

Contrariamente a estes hinos e aos hinos atonianos, não se encontra claramente expressa no acróstico a antinomia entre a distância a que o Sol está da terra e o facto de a sua luz ser vista pelos olhos e o seu calor apercebido na pele. Apenas o carácter incognoscível e misterioso do disco solar, ou antes, do deus que nele habita (Acr. 12,24; H 16). A sua acção vivificadora e alimentadora é muito pouco desenvolvida. Diz-se que é uma fonte universal de vida (Acr. 10,20; L 24) e que fez o cereal (Acr. 8,17; I 17), enquanto o Grande Hino descreve extensivamente toda a criação amoniana: deuses, que saíram da sua boca (GHAC, linhas 16, 111), homens que nasceram dos seus olhos (GHAC, linhas 17, 112), plantas (GHAC, linha 113) e animais domésticos (GHAC, linha 113). Dá o sopro da vida «aos que estão no ovo» (GHAC, linha 118), mesmo aos mais irritantes animais como ratos, pulgas e vermes (GHAC, linhas 119-122).

Com base em tudo isto, o acróstico pode considerar-se um texto próximo da nova teologia solar, mas sem os desenvolvimentos paracientíficos nem o rigor teológico que será apanágio de textos posteriores como os hinos atonianos ou os hinos ao deus Amon.

\section{Notas}

(1) Nomeadamente as inscrições do tecto do pórtico ocidental.

(2) A leitura Nawy é perfeitamente legítima, embora o seu significado, «o das duas mãos», esteja longe de ser claro.

(3) Veja-se, por exemplo, o túmulo do vizir Ramose (TT 55), também chamado Ramés.

(4) Referência TT 57, em Sheikh Abd el-Gurnah. Ver Wente (trad.), «The tomb of Kheruef», Epigraphic Survey, OIP 102, 1980.

(5) Isto é, o celeiro do Alto e do Baixo Egipto.

(6) De acordo com o título de uma obra célebre. Ver ASSMANN, Egyptian Solar Religion in the New Kingdom. Re, Amun and the crisis of Polytheism, 1994.

(7) Amen-hotep III ficou para a posteridade como um grande construtor. Data do seu reinado o belo templo de Lucsor (Ipet-resit), entre outras obras.

(8) ASSMANN, op. cit., p. 158.

(9) Tal como se comprova pelo nome teóforo de Amenemhat usado por sete reis, de um total de sessenta e sete, pertencentes às XII e XIII dinastias. Ver ARAÚJO, «Onomástica real», Dicionário do Antigo Egipto, pp. 642-649.

(10) ASSMANN, The Search for God in Ancient Egypt, pp. 201-208. 
(11) Durante o reinado de Akhenaton, o nome de Aton aparece sob duas formas distintas, a

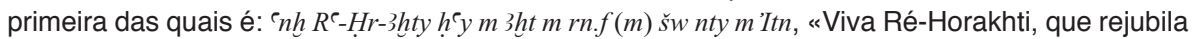
no horizonte, no seu nome de a luz que está no disco solar, dotado de vida eternamente, para sempre». No ano 12, vai desenvolver-se uma segunda fórmula canónica: ' $n h R^{\ulcorner} h k$ ’ $m$ 3hty h`y $m$ 3ht $m$ rn.fm šw (nty) il m 'Itn, «Viva Ré, soberano dos dois horizontes, que rejubila no horizonte, no seu nome de luz que vem do disco solar».

(12) WENTE (trad.), «The tomb of Kheruef», Epigraphic Survey, OIP 102, Chicago: University of Chicago Press, 1980.

(13) Lit. «deus divino», o que se afigura redundante.

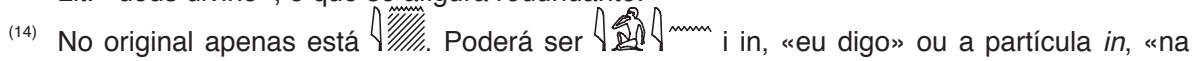
verdade, realmente». A tratar-se da preposição in, «para, pertencente a, de», isto significa que o deus Amon é amado por alguém, Kheruef, por exemplo. Infelizmente, o texto não permite determinar de quem se trata.

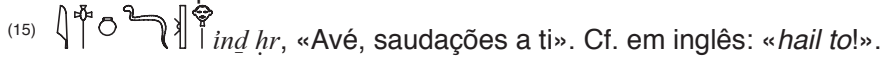

(16) hist «fronte, testa, semblante, a parte da frente». Note-se que o texto apresenta um plural, $h 3 w t$, pelo que pode também dar a ideia de peitorais poderosos, musculados do deus. ou talvez dos seus olhos poderosos, Wente e Murnane não utilizam o plural, traduzindo como «mighty of countenance», "de semblante poderoso». Ver, respectivamente, WENTE, op. cit., p. 35 e MURNANE, Texts from the Amarna Period in Egypt, p. 58.

(17) No original: $:$. Considerou-se um erro por hht nbt. Esta tradução concorda com a de WENTE, op. cit, p. 35.

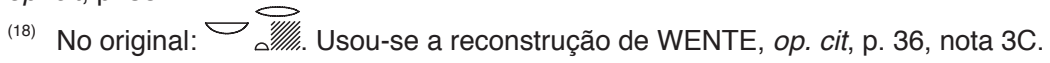

(19) Os dois conclaves: alusão às assembleias dos deuses do Alto e do Baixo Egipto.

(20) Na verdade, a grafia correcta é 1013 wi3.

(21) No original: 191 YI/I/, A presente reconstrução parece apropriada num hino solar.

(22) Lit. «Boca perfeita». Amon dirige-se às assembleias dos deuses como um excelente orador.

(23) De Por rs, «vigilante, acordado».

(24) É uma leitura possível do signo U28. Talvez Amon seja o «senhor da prosperidade». Uma vez que se trata de um hino solar, nada obsta a que aqui estivesse o verbo $\underline{d} 3 i$, «navegar», uma referência ao percurso do astro na sua barca. Esta hipótese é reforçada pela frase "como a luz».

(25) De acordo com o pensamento egípcio, o Sol punha-se na montanha ocidental de Tebas, denominada Manu. Ver FAULKNER, A Concise Dictionary of Middle Egyptian, p. 103.

(26) Optou-se pelo plural arcaico, de acordo com a reconstrução de WENTE, op. cit., p. 36, nota 6A.

(27) Kamutef, «o touro de sua mãe», um título característico de Min, um deus, ligado à fertilidade e representado de forma ictifálica.

(28) O termo akhu (plural de akh) não tem uma tradução exacta em português. O estado de akh atinge-se depois da morte e está destinado aos bem-aventurados.

(29) De acordo com a reconstrução de WENTE, op. cit., p. 37, nota 6C.

(30) Ibidem, nota 7D.

(31) Ibidem, nota 7E.

(32) Ibidem, nota $7 \mathrm{~J}$. 
Ibidem, nota $7 \mathrm{~K}$.

(34) Título real de Amon.

(35) A forma itw (pais) em plural arcaico.

(36) Este plural só faz sentido se a frase puder referir-se aos dois tipos tradicionais de magia: a magia branca e a magia negra. Os Egípcios praticavam ambas.

(37) A grafia correcta é $\triangle>$ km3, «atirar, produzir, criar».

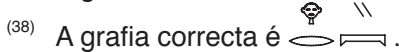

(39) BARGUET, Le Livre des Morts des Anciens Egyptiens, p. 182.

(40) O chamado Grande Hino a Amon, do Cairo, ou «Papiro 17 do Museu de Bulak», é anterior ao reinado de Amen-hotep IV IAkhenaton. Ver, respectivamente, BARUCQ e DAUMAS, Hymnes et Prières de l'Égypte Ancienne, p. 190, e ARAÚJO, op. cit., p. 61.

(41) BARUCQ e DAUMAS, op. cit., p. 182

(42) Assim é dito sobre Ré-Atum-Horakhti no hino gravado na estela do príncipe Horemheb (final da XVIII dinastia). Ver BARUCQ e DAUMAS, op. cit., p. 123.

(43) Ibidem, p. 189. A frase completa é: «Khepri, de sublime nascimento, que eleva a sua beleza do seio de Nut».

(44) É o caso de Amen-hotep II, em Shamash Edom, na campanha do ano 7 do seu reinado. Ver LALOUETTE, Thèbes ou la naissance d'un empire, p. 386.

(45) Ver DAVIES, The Rock Tombs of el-Amarna, vols. I-VI, 2004.

(46) Que para simplificar se designará daqui em diante simplesmente por Acr.

(47) KITCHEN, Poetry of Ancient Egypt, pp. 241-248.

(48) ASSMANN, The Search for God in Ancient Egypt, pp. 202-204.

\section{Bibliografia}

\section{Fontes}

BARUCQ, André; DAUMAS, François, Hymnes et Prières de l'Égypte Ancienne, Paris: Les Éditions du Cerf, 1980.

BARGUET, Paul, Le Livre des Morts des Anciens Egyptiens, Paris: Les Éditions du Cerf, 1998. KITCHEN, Kenneth, Poetry of Ancient Egypt, Jonsered: Paul Aströms Förlag, 1999.

MURNANE, William, Texts from the Amarna Period in Egypt, Atlanta: Scholars Press, 1994.

WENTE, Edward F. (trad.), «The tomb of Kheruef», Epigraphic Survey, OIP 102, Chicago: University of Chicago Press, 1980.

\section{Dicionários e gramáticas}

ARAÚJO, Luís Manuel de (dir.), Dicionário do Antigo Egipto, Lisboa: Editorial Caminho, 2001. 
BONNAMY, Yvonne; SADEK, Ashraf, Dictionnaire des Hiéroglyphes, Arles: Actes Sud, 2010.

FAULKNER, Raymond O., A Concise Dictionary of Middle Egyptian, Oxford: Griffith Institute, 1988.

GARDINER, Sir Alan, Egyptian Grammar, 3rd ed., Oxford: Griffith Institute, 2001.

\section{Bibliografia específica}

ARAÚJO, Luís Manuel de, O Clero do Deus Amon no Antigo Egipto, Lisboa: Edições Cosmos, 1999. ASSMANN, Jan, State and Religion in the New Kingdom, New Haven: Yale University, 1989.

ASSMANN, Jan, "Akhanyati's Theology of Light and Time», The Israel Academy of Sciences and Humanities Proceedings, vol. VII, $\mathrm{n}^{\circ}$ 4, 1992, pp. 143-176.

ASSMANN, Jan, Egyptian Solar Religion in the New Kingdom. Re, Amun and the crisis of Polytheism, Londres: Kegan Paul International, 1994.

ASSMANN, Jan, The Search for God in Ancient Egypt, Ithaca, Londres: Cornell University Press, 2001.

ASSMANN, Jan, Theological responses to Amarna, Penn State University, 2001.

ASSMANN, Jan, The Mind of Egypt. History and Meaning in the Time of the Pharaohs, Cambridge, Massachusetts, Londres: Harvard University Press, 2003.

ASSMANN, Jan, Death and Salvation in Ancient Egypt, Ithaca, Londres: Cornell University Press, 2005.

ASSMANN, Jan, «La naissance du monothéisme», Le Monde des Religions, Mars-Avril, 2008, pp. $40-41$.

CARREIRA, J. Nunes, Mito, Mundo e Monoteísmo, Mem Martins: Publ. Europa-América, 1994.

CARREIRA, J. Nunes, Literatura do Antigo Egipto, Mem Martins: Publ. Europa-América, 2005.

DAVIES, Norman de G., The Tomb of the vizier Ramose, Mond Excavations at Thebes 1, London: The Egypt Exploration Society, 1941.

DAVIES, Norman de G., The Rock Tombs of el-Amarna, vols. I-VI, reprint, Londres: The Egypt Exploration Society, 2004.

LALOUETTE, Claire, Thèbes ou la naissance d'un empire, Paris: Flammarion, 1995.

QUIRKE, Stephen, Le Culte de Rê, Paris: Champollion, Éditions du Rocher, 2004

SALES, José das Candeias, As Divindades Egípcias. Uma chave para a compreensão do Egipto antigo, Lisboa: Editorial Estampa, 1999. 